\title{
PERANCANGAN STRATEGI PELAYANAN BERBASIS PENGETAHUAN PADA KANTOR NOTARIS
}

\author{
Sukarti ${ }^{1}$, Sri karnila ${ }^{2}$ \\ ${ }^{12}$ Fakultas Ilmu Komputer, Informatics \& Business Institute Darmajaya \\ Jl. Z.A. Pagar Alam No. 93, Bandar Lampung \\ e-mail : kartidj@gmail.com, srikarnila@gmail.com
}

\begin{abstract}
The study resulted in a strategy design for certificate making service at the notary office. It was a case study at notary office of Theresia Dwi Wijayanti, S.H. the mechanism and work frame/ principle of certificate making service was still in the form of job instructions understood only by several employees, and this often made repeated questions at the service department and became a problem when the employee took permission not to come to work. Since the mechanism and work flow/ principle of the service was not vivid, and there were no any media for the service of making the authentic certificates, the mechanism and the work flow/ principles of services in making the certificates at the notary office.

The design of the strategy is facilitated with the service of certificate making that could be used as a media in knowledge share, became a knowledge management portal at the service department, so it would grow knowledge share culture (Knowledge Sharing) among the employees and the optimal service to the clients.

The system development method used in the study was Knowledge Management Roadmap method with these phases: business modeling, use-case modeling, analysis, design, and implementation. This method resulted in a strategy design for the service department to make certificates. Furthermore, the notary office would have a knowledge share media.
\end{abstract}

Keywords: Knowledge Management, Knowledge Sharing, Knowledge Management Roadmap

\begin{abstract}
Abstrak
Penelitian menghasilkan rancangan strategi untuk pelayanan pembuatan akta pada kantor Notaris, study kasus pada kantor Notaris Theresia Dwi Wijayanti, SH. Mekanisme dan alur kerja/prinsip pelayanan pembuatan akta masih berupa instruksi kerja, yang dipahami oleh beberapa pegawai saja, dan sering menjadi pertanyaan berulang pada bagian pelayanan serta menjadi kendala pada saat pegawai izin tidak masuk kerja. Karena mekanisme dan alur kerja/prinsip pelayanan belum jelas dan belum adanya media untuk pelayanan pembuatan akta otentik, mekanisme dan alur kerja/prinsip pelayanan dalam pembuatan akta pada kantor Notaris.

Rancangan strategi ini difasilitasi dengan aplikasi pelayanan pembuatan akta yang dapat digunakan sebagai media dalam berbagi pengetahuan, menjadi portal Knowledge Manajement pada bagian pelayanan, sehingga menumbuhkan budaya
\end{abstract}


penyebaran pengetahuan (Knowledge Sharing) diantara pegawai dan pelayanan optimal kepada klien.

Metode pengembangan sistem yang digunakan adalah Knowledge Management Roadmap dengan tahapan pemodelan bisnis, pemodelan use case, analisis, perancangan, dan implementasi. Dengan metode Knowledge Manajement Roadmap menghasilkan rancangan strategi untuk bagian pelayanan pembuatan akta dan kantor Notaris memiliki sebuah media berbagi pengetahuan.

Kata kunci: Manajemen Pengetahuan, Knowledge Sharing, Knowledge Manajement Roadmap.

\section{PENDAHULUAN}

\subsection{Latar Belakang}

Pengelolaan pengetahuan (knowledge management), menjadi salah satu metode peningkatan produktifitas suatu organisasi, perusahaan atau instansi. Pemanfaatan sumber daya manusia melalui potensi kreativitas dan inovasi, agar dapat meningkatkan produktivitas suatu organisasi. Berbagi pengetahuan (knowledge sharing) merupakan salah satu metode dalam knowledge management yang digunakan untuk memberikan kesempatan kepada anggota suatu organisasi, instansi atau perusahaan untuk berbagi ilmu pengetahuan, teknik, pengalaman dan ide yang mereka miliki kepada anggota lainnya. Berbagi pengetahuan hanya dapat dilakukan bilamana setiap anggota memiliki kesempatan yang luas dalam menyampaikan pendapat, ide, kritikan, dan komentarnya kepada anggota lainnya. Peran berbagi pengetahuan dikalangan karyawan menjadi amat penting untuk meningkatkan kemampuan karyawan agar mampu berpikir secara logika yang diharapkan akan menghasilkan suatu bentuk inovasi [4].

Kantor Notaris Theresia Dwi Wijayanti, SH merupakan kantor pejabat umum yang bergerak di bidang jasa resmi pembuatan akta otentik. Di Kantor Notaris Theresia Dwi Wijayanti, Sarjana Hukum belum ada mekanisme serta alur kerja atau prinsip pelayanan pembuatan akta yang jelas, alur kerja/prinsip pelayanan hanya diketahui oleh beberapa pegawai, masih ada pegawai yang belum memahami alur kerja/prinsip pelayanan dengan baik, saat melakukan pelayanan yang serupa. Dari latar belakang masalah tersebut diatas maka, membutuhkan penerapan manajemen pengetahuan, mencakup perancangan strategi pelayanan berbasis pengetahuan, mekanisme dan alur kerja/prinsip pelayanan pembuatan akta yang jelas, dan implementasi media sharing berupa portal pengetahuan bagi Kantor Notaris Theresia Dwi Wijayanti, Sarjana Hukum.

\subsection{Landasan Teori}

Pengetahuan adalah informasi yang kontekstual, relevan dan dapat dilakukan, pengetahuan sangat berbeda dari data dan informasi dalam konteks teknologi informasi, data adalah suatu kumpulan fakta, pengukuran dan statistik sedangkan informasi adalah data yang diorganisasi atau diproses tepat waktu (yaitu kesimpulan dari data ditarik di dalam batasan waktu yang dapat diterapkan) dan akurat (yaitu mengenai data yang asli) [3]. 


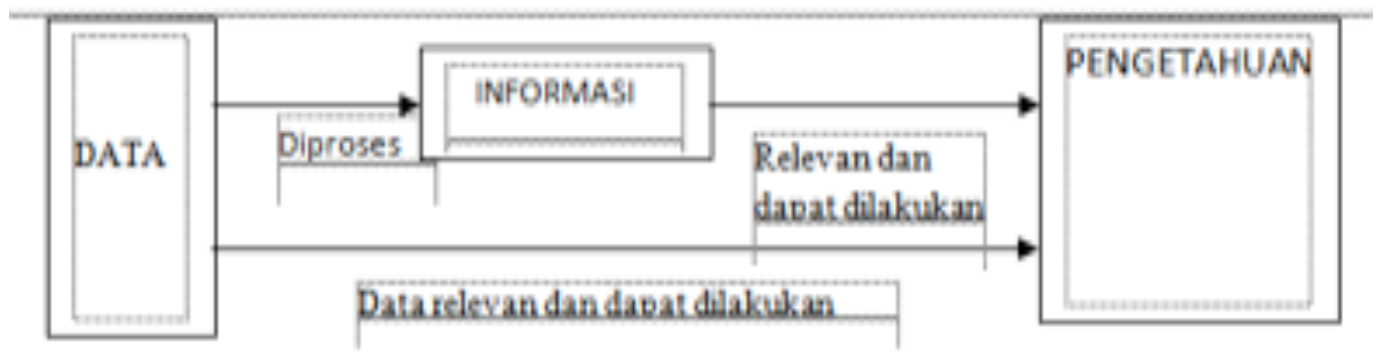

Gambar 1. Data, informasi dan pengetahuan [3]

Secara garis besar, pengetahuan (knowledge) dibagi menjadi 2 dimensi [3] yaitu:

a. Tacit knowledge adalah pengetahuan tersembunyi yang didapatkan dari pengalaman, kegiatan-kegiatan yang dilakukan, dan susah didefinisikan di mana biasanya dibagikan lewat diskusi-diskusi, cerita-cerita. Tacit knowledge diartikan sebagai suatu pengetahuan yang personal, spesifik, dan umumnya susah diformalisasi dan dikomunikasi kepada pihak lain.

b. Explicit knowledge adalah pengetahuan manusia yang berada di luar kepala, sudah diformulasikan, biasanya disajikan dalam bentuk tulisan misalnya peraturan, bukubuku literatur-literatur, dokumen, jurnal dan lain-lain. Sifat dari explicit knowledge adalah tercetak dalam kode-kode, deklaratif, formal dan hard (keras). Dalam organisasi proses penyebaran/sharing pengetahuan akan membantu pencapaian tujuan organisasi. Explicit atau codified knowledge diartikan sebagai pengetahuan yang dapat ditransformasikan dalam bentuk formal dan bahasa yang sistematis.

Penciptaan pengetahuan adalah pembangkitan insigt baru, gagasan atau rutin. Empat pola dasar penciptaan pengetahuan yang dikenal dengan The Spiral of Knowledge, seperti tersaji dalam gambar 2.

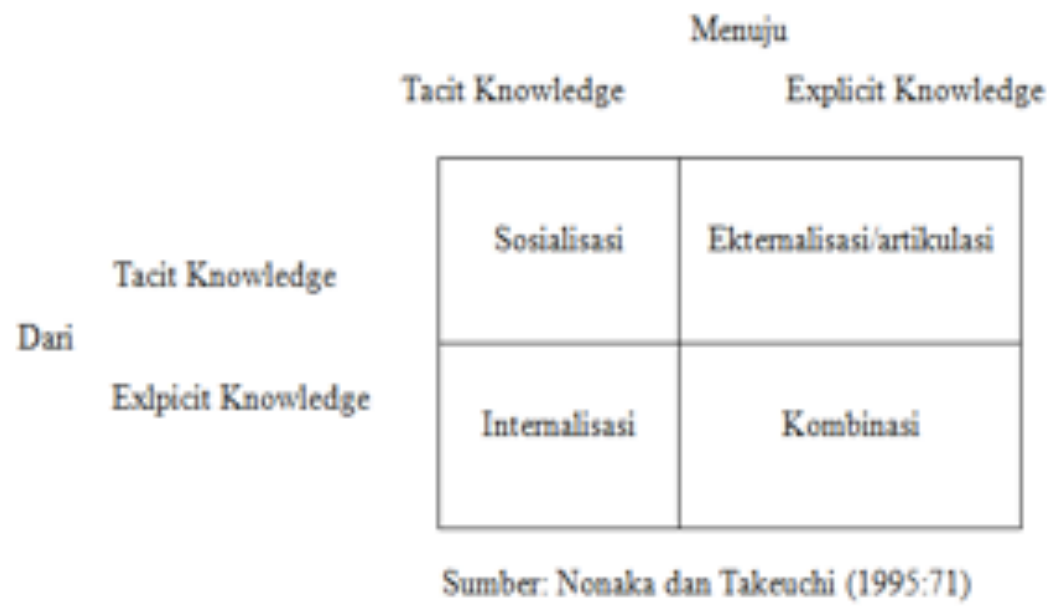

Gambar 2. Spiral Of Knowledge

a. Sosialisasi, mengacu pada konversi pengetahuan tersembunyi ke pengetahuan tersembunyi yang baru atau proses sharing dan penciptaan tacit knowledge 
melalui interaksi sosial, pengalaman langsung dan pengalaman bersama antar anggota organisasional. Saling berbagi antar tacit knowledge, umumnya tanpa melibatkan hal-hal formal, misalnya sharing budaya organisasi antara anggota organisasi yang lama dengan anggota yang baru dengan tujuan anggota yang baru mampu beradaptasi dengan budaya organisasi.

b. Eksternalisasi/artikulasi, mengkonversi tacit knowledge menjadi explicit knowledge melalui proses dialog dan refleksi, biasanya menggunakan metaformetafor yang dapat dipahami bersama. Ekternalisasi mengacu pada mengubah pengetahuan tersembunyi ke pengetahuan eksplisit baru.

c. Internalisasi, merubah explicit knowledge menuju tacit knowledge atau mengacu pada penciptaan pengetahuan tersembunyi baru dari pengetahuan eksplisit. Jargon yang paling populer untuk menjelaskan internalisasi adalah learning by doing, merupakan proses pembelajaran dan akuisisi Knowledge yang dilakukan oleh anggota organisasi terhadap explicit Knowledge yang disebarkan keseluruh organisasi melalui pengalaman sendiri sehingga menjadi tacit Knowledge anggota organisasi.

d. Kombinasi, mengacu pada penciptaan pengetahuan eksplisit baru dengan menggabungkan, menggolongkan, menggolongkan kembali dan menyatukan pengetahuan eksplisit yang sudah ada. Mengkombinasikan antar explicit knowledge atau proses konversi explicit knowledge menjadi explicit knowledge yang baru yang dipunyai oleh individu lain dengan explicit knowledge yang dipunyai oleh diri sendiri. 


\subsubsection{Manajemen Pengetahuan}

Siklus manajemen pengetahuan merupakan sebuah fase yang menjelaskan penangkapan (capture), penciptaan (creation), kodifikas (codification), penyebarluasan (sharing), pengaksesan (accessing), aplikasi, dan penggunaan kembali pengetahuna yang berada dalam sebuah organisasi[2]. Model KMS mengakomodasi kebutuhan data, informasi dan pengetahuan untuk melakukan peringatan dini, menentukan sanksi akademik, dan merekomendasi beasiswa.

\subsubsection{Unified Modeling Language (UML)}

Pemodelan yang digunakan untuk penyederhanaan permasalahanpermasalahan kompleks sedemikian rupa sehingga lebih mudah dipelajari dan dipahami. Unified Modeling Language (UML) adalah alat bantu (tool) untuk pemodelan sistem, "UML" adalah bahasa yang dapat digunakan untuk spesifikasi, visualisasi, dan dokumentasi sistem objek-oriented software pada fase pengembangan. UML adalah bahasa pemodelan untuk sistem atau perangkat lunak yang berparadigma berorientasi objek [1].

\section{METODE PENELITIAN}

Pengembangan Knowledge Management System (KMS) bagi kantor Notaris Theresia Dwi Wijayanti, Sarjana Hukum, khususnya bagian pelayanan, penganalisisan dan perancangan sistem menggunakan metode Knowledge Management Roadmap. Knowledge Management Roadmap membantu pengembangan implementasi Knowledge Management System (KMS). Ada pun langkah-langkah yang dilakukan sebagai berikut:

a. Evaluasi Infrastruktur

b. Analisis, Desain dan Pengembangan KMS

c. Pengembangan Bisnis

d. Evaluasi

Tahapan-tahapan di atas dirinci menjadi Knowledge Managemen Roadmap sebagai berikut :

\begin{tabular}{|l|}
\hline 3.1 Evaluasi Infrastruktur \\
3.1.1 Analisis Infrastruktur pelayanan kantor Notaris yang sudah ada \\
3.1.2 Penyelarasan Strategi Bisnis dengan Manajemen Pengetahuan \\
\hline 3.2 Analisis, Desan dan Pengembangan KMS \\
3.2.1 Desain dan Arsitektur Knowledge Management System pelayanan \\
3.2.2 Pengembangan KMS bagian pelayanan \\
\hline 3.3 Pengembangan Bisnis \\
3.3.1 Tahapan Pengembangan Sistem \\
\hline 3.4 Evaluasi \\
\hline
\end{tabular}

Gambar 3. Knowledge Management Roadmap 


\subsection{Pengembangan Sistem}

Dalam pengembangan sistem KMS, menggunakan analisis dan desain beorientasi objek. Orientasi objek merupakan suatu teknik menyelesaikan masalah yang muncul dalam perancangan atau pun pengembangan perangkat lunak. Alat yang digunakan yaitu Unified Modelling Language (UML).

\subsection{Tahapan Pengembangan Sistem}

Dalam proses tahapan pengembangan sistem dilakukan beberapa langkah. Tahapan pengembangan sistem KMS yang dilakukan dalam hal ini adalah diperlihatkan dalam Gambar 4

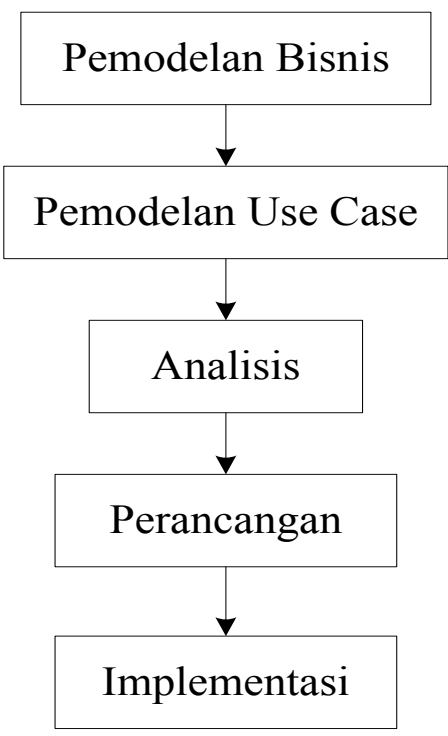

Gambar 4. Tahapan Pengembangan Sistem [1]

\section{HASIL DAN PEMBAHASAN}

\subsection{Hasil}

Model bisnis (rool bisnis) yang dihasilkan memberikan gambaran kepada bagian pelayanan dalam menjalankan bisnis proses dari bisnisnya dan objek yang mendukung bisnisnya, model bisnis ditunjukkan dengan use case. 


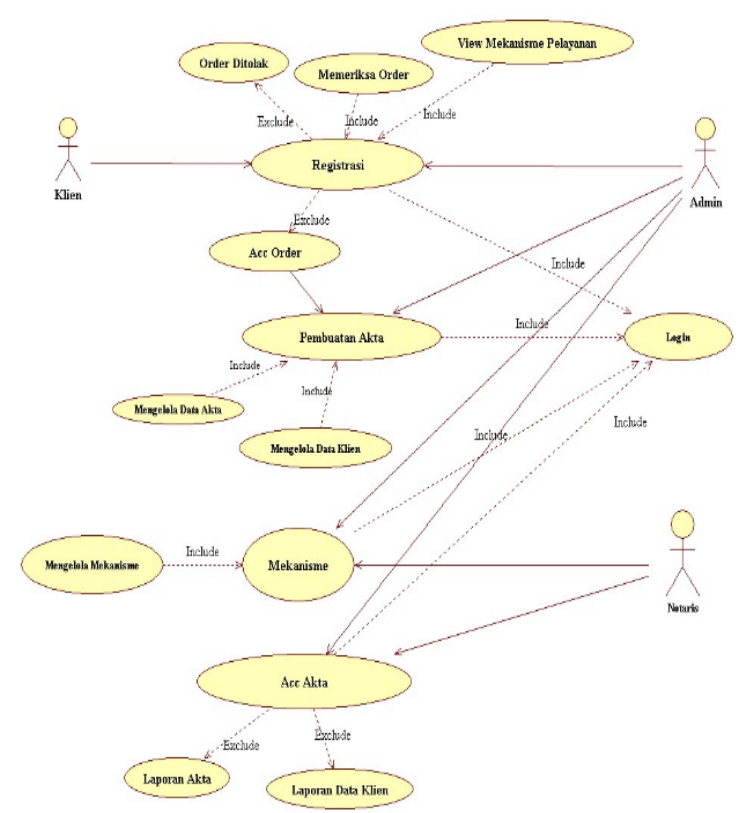

Gambar 5. Use Case Diagram KMS Pelayanan.

Use Case Diagram ini menggambarkan hubungan aktor dengan aktivitas yang ada di dalam sistem. Aktor yang ada di dalam sistem terdiri dari Klien, Admin dan Notaris, yang mana aktor-aktor ini akan terhubung dengan Use Case atau aktivitas yang ada di dalam lingkungan sistem. Use Case di dalam lingkungan sistem ini terdiri dari registrasi, pembuatan akta, mekanisme dan Acc Akta.

\subsection{Pembahasan}

\subsubsection{Activity Diagram}

Menggambarkan urutan aktifitas yang terjadi pada KMS, yang digambarkan seperti pada activity berikut :

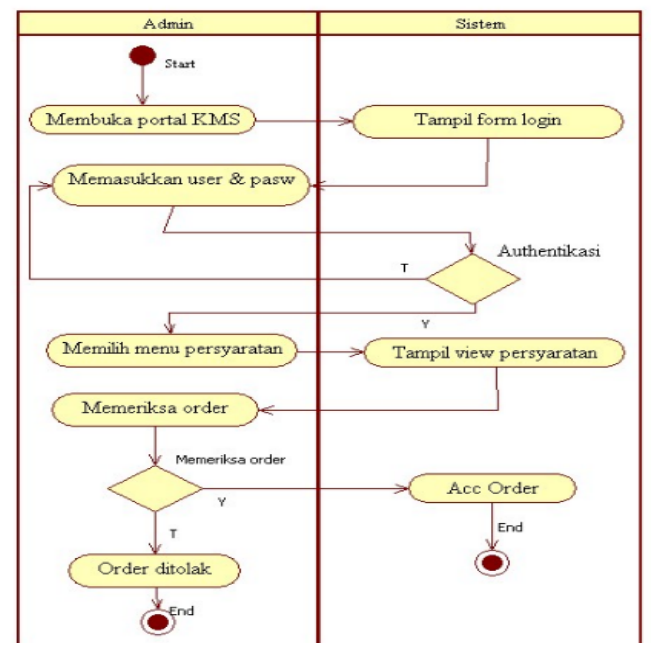

Gambar 6. Activity Diagram Registrasi Pembuatan Akta 


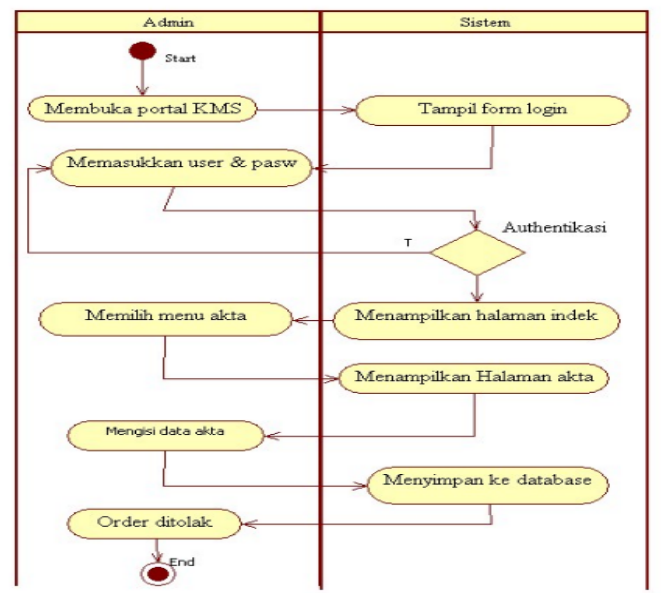

Gambar 7. Activity Diagram Pembuatan Akta

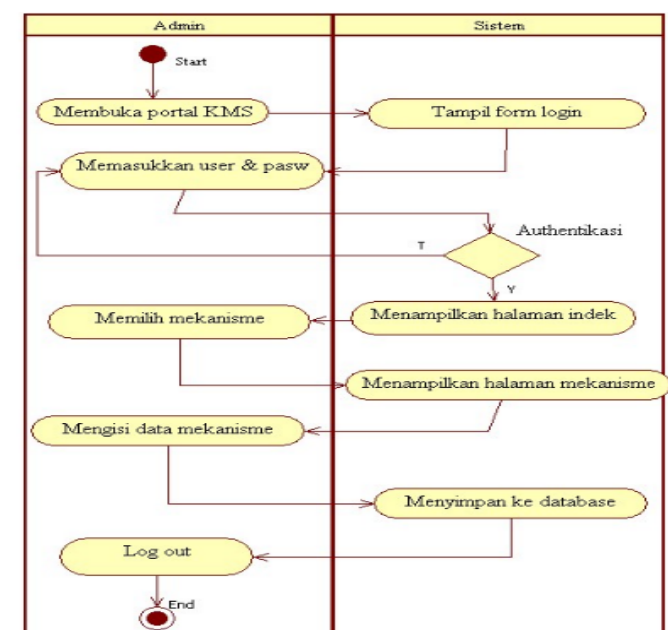

Gambar 8. Activity Diagram Mekanisme

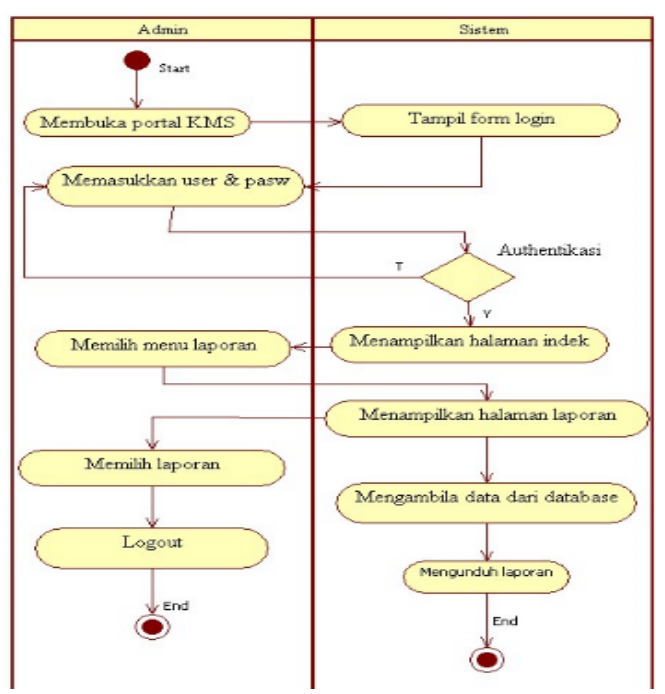

Gambar 9. Activity Diagram Mengelola Acc Akta 


\subsubsection{Sequence Diagram}

Sequence Diagram menggambarkan state (kondisi) yang dimiliki oleh suatu objek dari suatu class. Proses yang berjalan dalam sistem KMS ini dijelaskan dengan Sequence Diagram, diantaranya:

a. Sequence Diagram Registrasi

Sequence diagram registrasi menjelaskan rangkaian kondisi ketika pengguna (admin pelayanan) akan melakukan registrasi dan melihat persyaratan registrasi pembutan akta. Untuk lebih jelas alur proses registrasi pembuatan akta ini dapat dilihat pada Gambar 10 berikut.

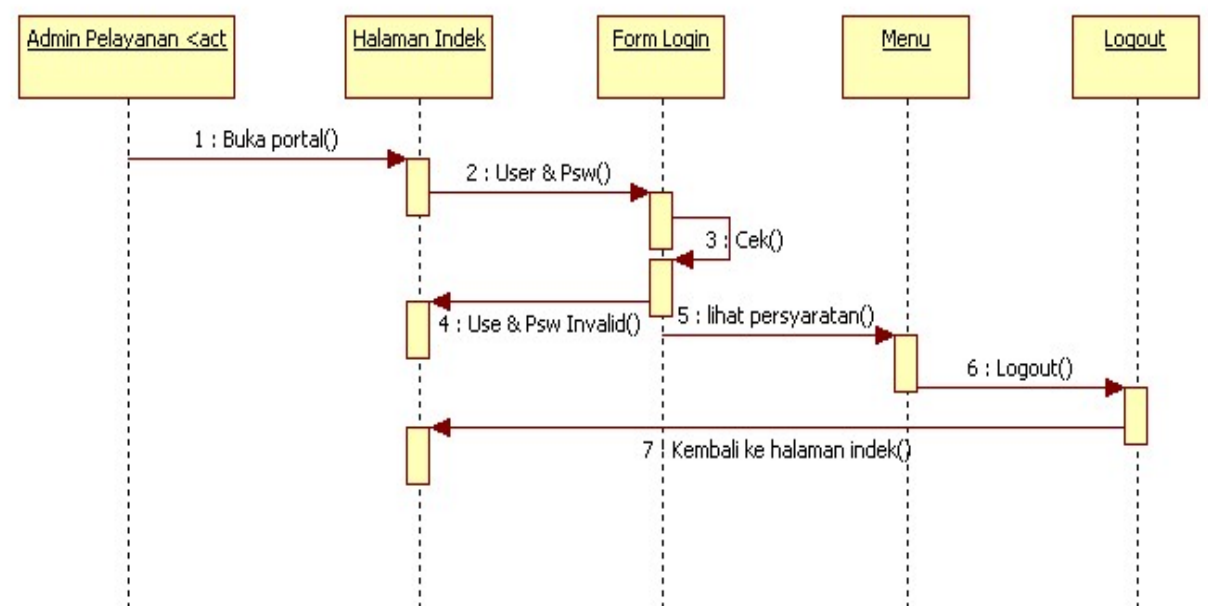

Gambar 10. Sequence Diagram Registrasi

b. Sequence Diagram Pembuatan Akta

Sequence diagram pembuatan akta menjelaskan rangkaian kondisi ketika pengguna (admin pelayanan) akan melakukan pembuatan akta, dimana sebelum membuat akta admin terlebih dahulu harus mengisi data klien, baru setelah itu dilanjutkan dengan mengisi data akta. Untuk lebih jelas alur proses pembuatan aktaini dapat dilihat pada gambar 11 berikut.

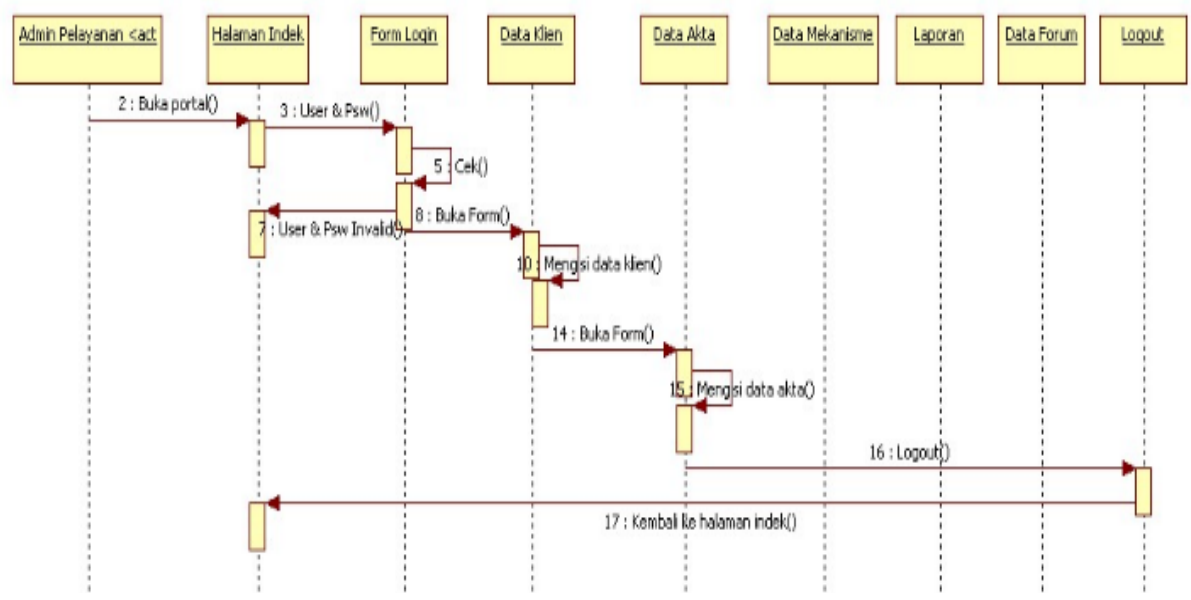

Gambar 11. Sequence Diagram Pembuatan Akta 
c. Sequence Diagram Acc Akta

Sequence diagram Acc akta menjelaskan rangkaian kondisi ketika pengguna (admin/Notaris) akan melakukan Acc akta, dimana admin/Notaris harus mendownload file akta, baru setelah itu dilanjutkan dengan mengecek dan mengkoreksi akta, dan terakhir melakukan acc akta.

\subsubsection{Class Diagram}

Class Diagram merupakan struktur statis class di dalam sistem. Pada sistem manajemen pengetahuan ini, terdapat 7 class.

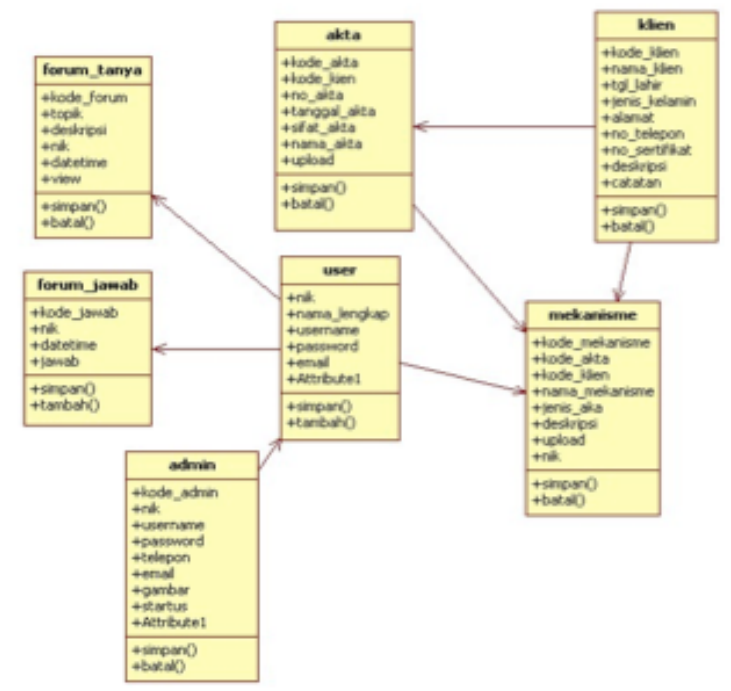

Gambar 12. Class Diagram Knowledge Management System Pelayanan

\section{SIMPULAN}

Berdasarkan hasil penelitian dan pembahasan dari bab sebelumnya maka dapat diambil simpulan bahwa Manajemen pengetahuan pelayanan pembuatan akta sangat berperan penting dalam mendukung strategi pelayanan pembuatan akta otentik pada kantor Notaris Theresia Dwi Wijayanti, Sarjana Hukum. Dengan interface menjadi media informasi sehingga terciptanya budaya berbagi pengetahuan pelayanan pembuatan akta, menumbuhkan budaya penyebaran pengetahuan (Knowledge Sharing) diantara pegawai. Dan saat pertukaran atau kekosongan pegawai tidak lagi menjadi masalah dan pelayanan kepada klien lebih optimal. 


\section{DAFTAR PUSTAKA}

[1] Nugroho, A., Rational Rose: Pemodelan berorientasi objek, Penerbit Informatika, Bandung, 2008.

[2] Tan, Robby, Perancangan Model Manajemen Pengetahuan Menggunakan Model Nonaka Takeuchi (Studi Kasus Administrasi Akademik), Jurnal Informatika Vol 6 No.1. Juni 2010, Bandung, 2010.

[3] Turban, E., Aroson, E. J., \& Liang, P. T., Decision Support System And Intelligent Systems (Sistem Pendukung Keputusan Dan Sistem Cerdas) jilid 1, Edisi 7, Penerbit ANDI, Yogyakarta, 2005

[4] Setiarso, B., Harjanto, N., Triyono., \& Subagyo, H., Penerapan Knowledge Management Pada Organiasasi, Penerbit Graha Ilmu, Yogyakarta, 2009. 